\title{
DESIGN DE JOIAS, MATERIAIS E PROCESSOS: avaliação dimensional de moldes de borracha de silicone por digitalização tridimensional a laser
}

\author{
Mariana Pohlmann \\ PPGE3M/LdSM - UFRGS \\ marianapohlmann@gmail.com \\ Fabio Pinto da Silva \\ DEG/PGDESIGN/LdSM - UFRGS \\ fabio.silva@ufrgs.br \\ Wilson Kindlein Júnior \\ DEMAT/PGDESIGN/LdSM \\ kindlein@portoweb.com.br
}

\begin{abstract}
Resumo: O design é uma excelente ferramenta de competitividade. Na fabricação de joias em larga escala, o designer deve conhecer todos os processos envolvidos. Tradicionalmente, o método mais adequado para a reprodução de peças metálicas é a microfusão. Neste processo, a produção dos moldes de borracha é o ponto com maior perda de precisão. Este trabalho tem como objetivo quantificar os erros dimensionais da etapa de produção do molde de borracha de silicone. Diferentes amostras de borracha de silicone apresentam diferentes taxas de encolhimento. Verificou-se que a dureza, o tempo e a temperatura não têm relação com a taxa de encolhimento. A contração pode ser atribuída predominantemente a reações físico-químicas ocorridas nos processos de vulcanização e cura dos materiais.
\end{abstract}

Palavras-chave: Design de joias, molde de borracha de silicone, digitalização 3D a laser.

\begin{abstract}
Design is an excellent tool for the competitiveness. On jewelry large scale manufacture, the designer must know all the involved processes. Traditionally, investment microcasting is the most suitable reproduction method of metal parts. In this process, the rubber moldings production is the point with the largest loss of precision. This study aims to quantify the dimensional errors of silicone rubber molding production stage. Different silicone rubber samples have different shrinkage rates. Hardness, temperature and time have no relation to the shrinkage rate. Thus, the contraction can be attributed predominantly to physicochemical reactions occurring in the processes of vulcanization and curing of the materials.
\end{abstract}

Keywords: Jewelry design, silicone rubber molding, 3D laser scanning. 


\section{INTRODUÇÃO}

O setor joalheiro, de modo geral, ainda faz uso de processos de concepção e fabricação tradicionais e mostra-se resistente à incorporação de novos recursos tecnológicos. Entretanto, espera-se que a indústria joalheira nacionais insira-se neste ambiente atualizado, estando mais capacitada a concorrer no mercado internacional (WINKLER, 2008).

$\mathrm{O}$ design vem se mostrando uma excelente ferramenta de competitividade às empresas de todos os setores. Além de ser o profissional responsável pela criação enquanto arte, o designer é, atualmente, o responsável pela criação considerando o posicionamento da joia, enquanto produto, e as relações com o usuário, enquanto consumidor. No que tange a fabricação de joias em larga escala, o designer deve conhecer todo o processo envolvido na produção das peças: ourivesaria, cravação, gravação, esmaltação e polimento. Noções de gemologia e de metalurgia também são importantes. Desta forma o profissional tem subsídios para um efetivo trabalho de criação e detalhamento das peças. Na concepção de joias, o designer trabalha sob grande demanda de fluxo criativo. Para supri-lo, o conhecimento acerca de práticas específicas torna-se imprescindível (RICK, 2006; REBELLO, 2007).

Tradicionalmente, o método mais adequado para a reprodução de pequenas peças metálicas é a microfusão (ou fundição por cera perdida), visto que possibilita total liberdade de forma na construção da matriz (RICK, 2006; REBELLO, 2007; GIULIANO, 2008). Basicamente, na microfusão um modelo produzido em cera origina uma réplica em metal. Essa técnica pode ser obtida por meio de dois métodos distintos: o direto e o indireto. No método direto, os modelos (em cera) e os moldes (por exemplo, em gesso) são perdidos ao longo do processo de fundição, não permitindo, portanto, a seriação de uma peça (MIDGLEY, 1986). Para este fim, emprega-se o método indireto, que consiste na construção de um molde permanente (geralmente, borracha de silicone) no qual a cera pode ser injetada repetidas vezes. Este método é denominado indireto, pois não gera a peça final em metal diretamente, mas sim, uma peça intermediária em cera (MIDGLEY, 1986; GIULIANO, 2008).

Em estudo realizado por Pohlmann et. al. (2013), a microfusão foi avaliada quanto aos erros dimensionais ocorridos ao longo das etapas que abrangem este processo. Para tanto, a réplica do hombre murciélago (peça pré-colombiana que integra o acervo do Museu do Ouro, em Bogotá, na Colômbia) foi digitalizada (Figura 1a), reproduzida por fresamento em cera (Figura 1b) e o modelo foi submetido ao processo de microfusão (Figura1c).
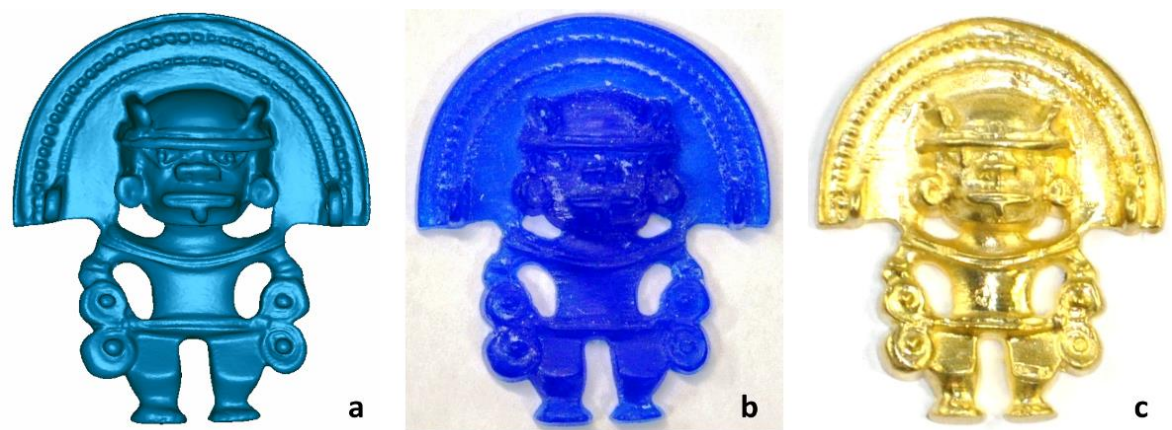

Figura 1 - Processo de reprodução do hombre murciélago. Modelo virtual (a), modelo usinado em cera (b), modelo final em metal (c).

Fonte: Pohlmann (2013). 
As análises realizadas indicaram que o principal ponto de perda de precisão é a etapa de confecção dos moldes de borracha de silicone e injeção de cera (Figura 2).

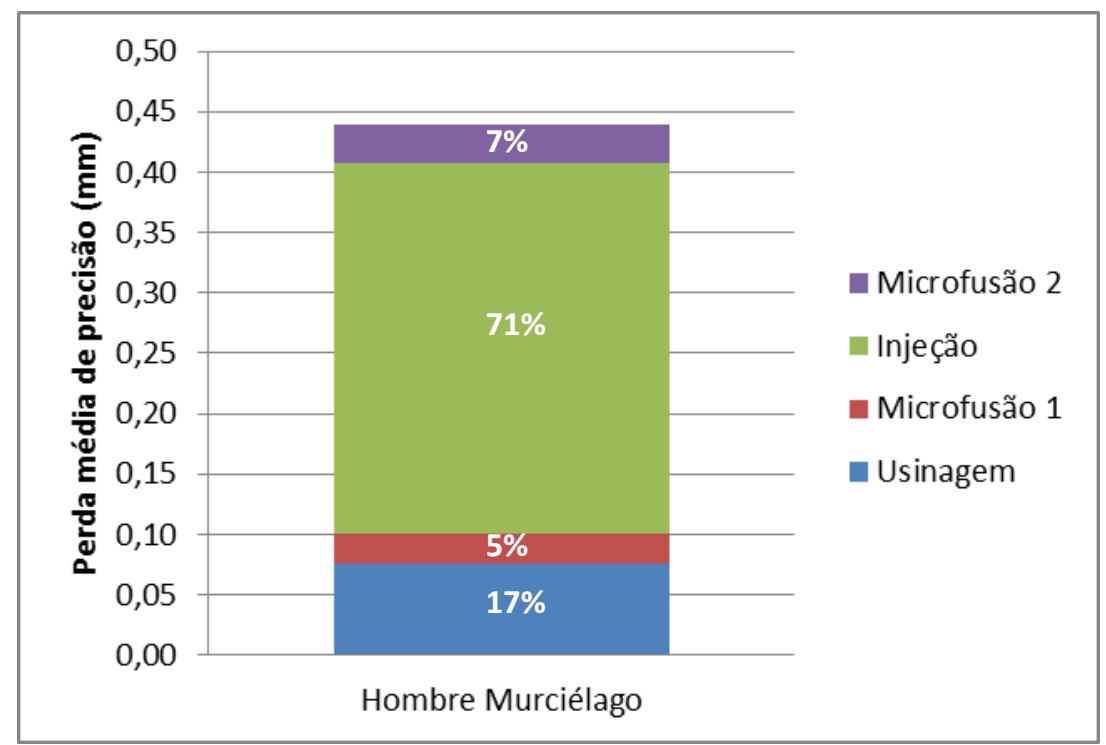

Figura 2 - Erros dimensionais ocorridos em função das etapas de produção do hombre murciélago. A etapa de Usinagem refere-se à obtenção de modelos em cera; a Microfusão 1 , à produção das peças piloto em metal; a Injeção, à etapa de produção dos moldes de borracha de silicone e injeção de cera; e Microfusão 2, à produção das peças finais em metal.

Fonte: Pohlmann (2013).

Segundo Kliauga e Ferrante (2009), os moldes feitos a partir de borracha podem tanto servir para fundição de ligas de baixo ponto de fusão (estanho e antimônio ou estanho e chumbo), quanto para a reprodução de moldes de cera. Como características fundamentais as borrachas apresentam grande capacidade de reprodução de detalhes, baixa aderência, resistência ao envelhecimento, ao rasgamento e ao calor. Neste trabalho, foram utilizadas cinco amostras de borracha de silicone vulcanizadas sob calor e pressão e uma amostra de borracha de silicone de cura a frio.

A borracha de silicone é composta por cloretos orgânicos e silicone (polímero composto de cadeias de silício, oxigênio e hidrogênio). O silicone tem como agentes vulcanizadores o enxofre e o óxido de zinco. Os moldes produzidos podem ser utilizados para a reprodução de modelos em cera e para fundição de ligas de estanho, chumbo e bismuto. Já as borrachas de cura a frio têm como maior vantagem a estabilidade volumétrica durante a cura, oferecendo, portanto, uma reprodução mais precisa. Geralmente, o processo de vulcanização leva 24 horas, mas já existem borrachas de cura a frio que curam em algumas horas (KLIAUGA e FERRANTE, 2009).

Posto esse cenário, este trabalho visa uma contribuição ao estudo de materiais e processos empregados na confecção de joias. Essa ação tem como objetivo quantificar os erros dimensionais da etapa de produção do molde de borracha de silicone através de um estudo de caso. Neste sentido, foi realizada uma análise comparativa dos resultados deste processo com $o$ auxílio da digitalização tridimensional. 


\section{MATERIAIS E MÉTODOS}

Para a produção dos moldes de borracha de silicone, foram selecionados materiais com ampla utilização na indústria joalheira nacional, sendo cinco vulcanizáveis e um de cura a frio. As amostras apresentam diferenciação quanto à dureza e aos parâmetros (tempo e temperatura) para vulcanização/cura (Tabela 1). A produção dos moldes foi realizada no Laboratório de Caracterização dos Materiais (LACAR/UFRGS) com os parâmetros para vulcanização/cura fornecidos pelos fabricantes.

Tabela 1 - Características das borrachas de silicone e parâmetros para vulcanização.

\begin{tabular}{llll}
\hline & Dureza $($ Shore A) & Tempo $(\min )$ & Temperatura $\left({ }^{\circ} \mathrm{C}\right)$ \\
\hline Molde 1 & 32 & 90 & 85 \\
\hline Molde 2 & 36 & 50 & 150 \\
\hline Molde 3 & 40 & 110 & 85 \\
\hline Molde 4 & 43 & 50 & 150 \\
\hline Molde 5 & 48 & 50 & 150 \\
\hline Molde 6 & 40 & 240 & - \\
\hline
\end{tabular}

Fonte: Elaborado pelo autor, com base na pesquisa realizada.

Depois de finalizado o processo de vulcanização/cura, os moldes de borracha de silicone foram abertos com o auxílio de uma lâmina de bisturi, por um processo inteiramente manual (Figura 3).
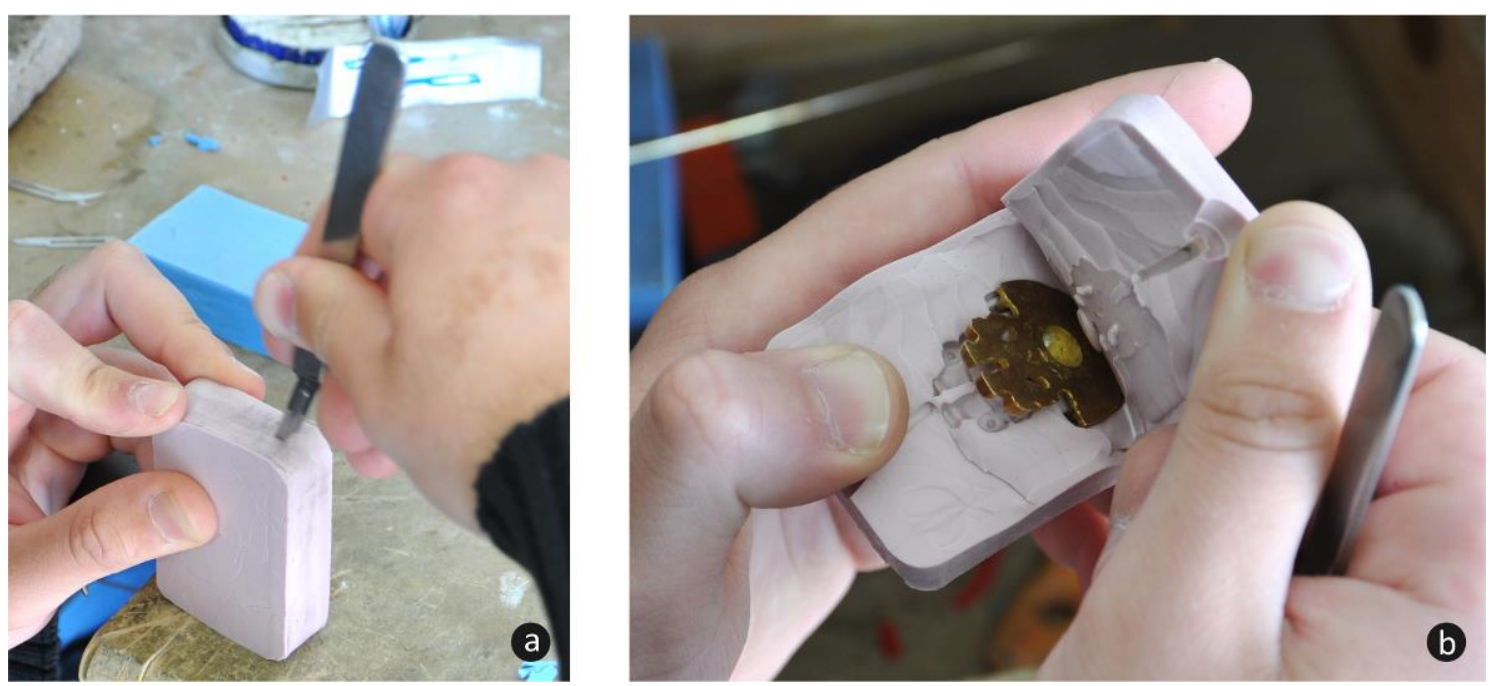

Figura 3 - Abertura do molde de borracha de silicone. (a) início do processo de abertura do molde; e (b) molde parcialmente aberto revelando o modelo metálico em seu interior.

Fonte: Elaborado pelo autor, com base na pesquisa realizada.

A principal ferramenta analítica aplicada como método de comparação entre os resultados dos moldes de borracha de silicone e a peça original foi a digitalização tridimensional a laser. Para tanto, foi utilizado o Scanner 3D modelo Digimill 3D, marca Tecnodrill ${ }^{\circledR}$ (Figura 4), instalado nas dependências do Laboratório de Design e Seleção de Materiais (LdSM/UFRGS). Este é um equipamento híbrido: em seu cabeçote para usinagem CNC pode ser acoplado um cabeçote emissor de laser pontual modelo ConoProbe 1.000, marca Optimet ${ }^{\circledR}$. 


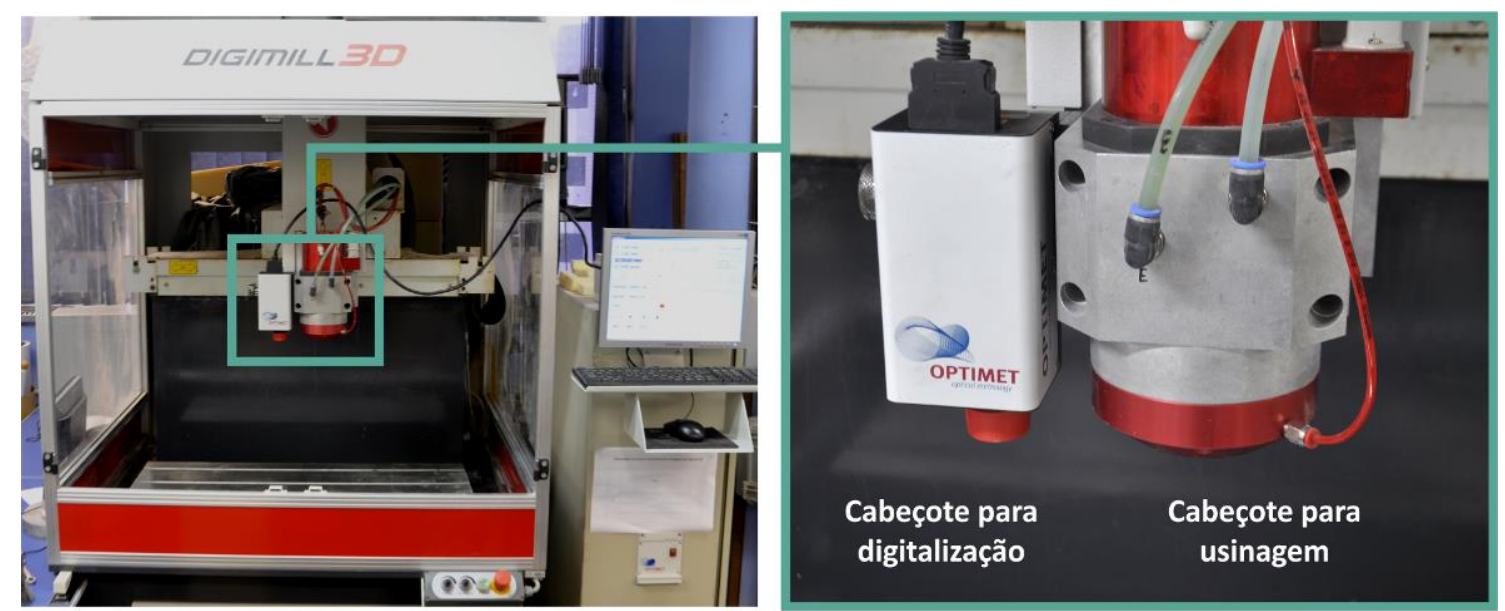

Figura 4 - Sistema de digitalização tridimensional. Em destaque, o cabeçote de digitalização (Optimet) acoplado no cabeçote de usinagem CNC (Digimill 3D). LdSM/UFRGS.

Fonte: Elaborado pelo autor, com base na pesquisa realizada.

Os resultados foram avaliados em relação ao encolhimento linear (Figura 5) dos moldes de borracha de silicone e à fidedignidade da reprodução dos detalhes da peça utilizada como referência.

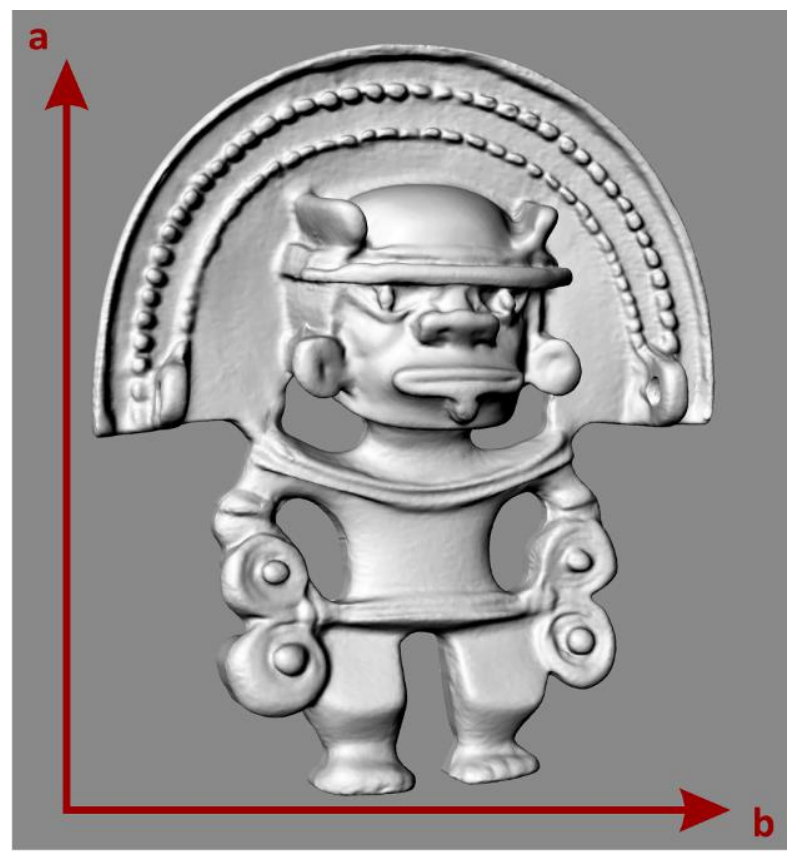

Figura 5 - Eixos longitudinal (a) e transversal (b) para avaliação da taxa de encolhimento dos moldes de borracha de silicone.

Fonte: Elaborado pelo autor, com base na pesquisa realizada.

\section{RESULTADOS}

Com o auxílio do o software Geomagic Qualify ${ }^{\mathrm{TM}}$, a nuvem de pontos obtida com a digitalização tridimensional foi sobreposta à superfície da peça utilizada como referência. A partir das imagens geradas, foi possível calcular o encolhimento linear dos moldes (Figura 6). De maneira geral, pode-se observar que os moldes (em verde) estão menores que a peça modelo (cinza). Com o cálculo do encolhimento médio das amostras, pode-se dizer que houve uma diminuição de $2,8 \%$ do tamanho dos moldes. 


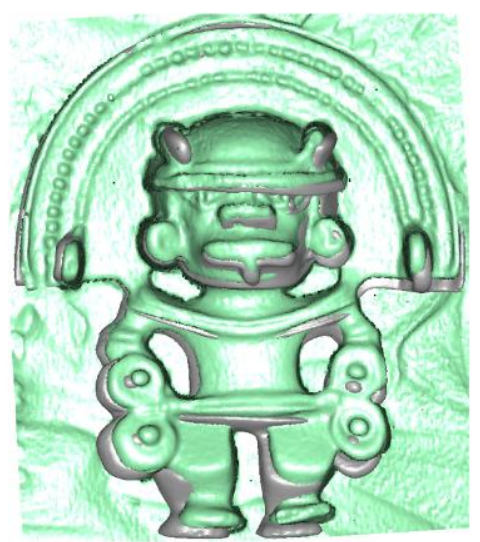

a
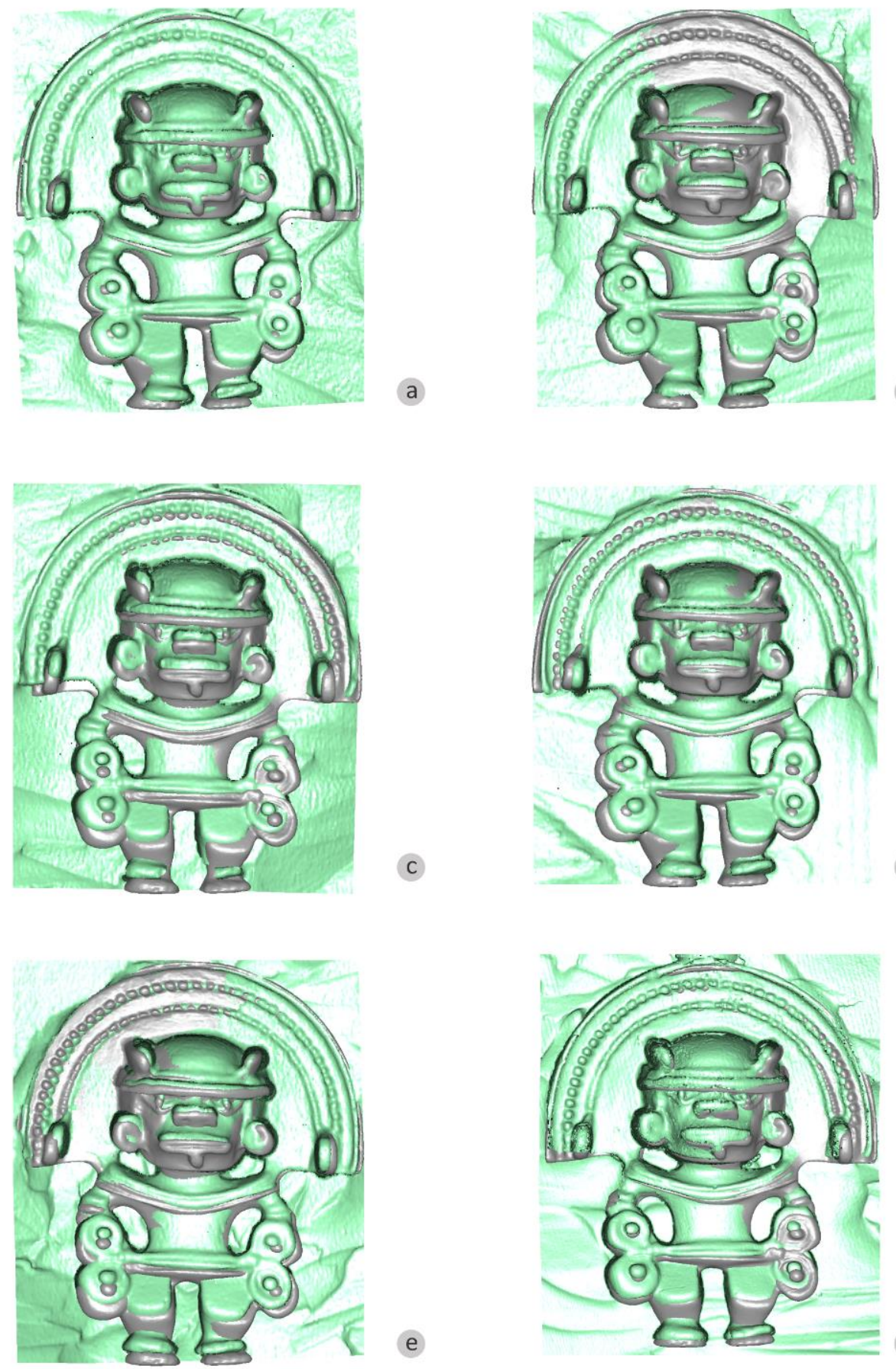

e

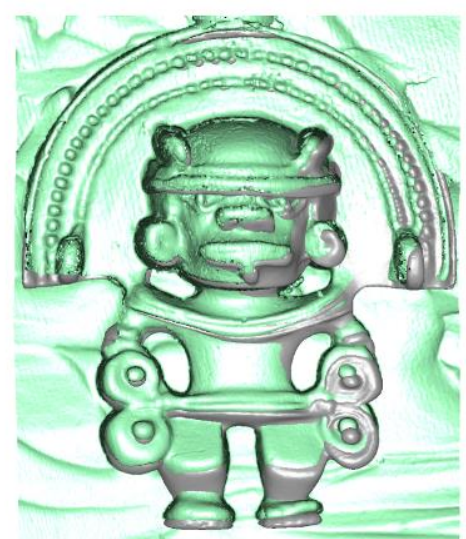

Figura 6 - Sobreposição virtual mostrando a diminuição do tamanho dos moldes. Os modelos na cor cinza correspondem à peça de referência utilizada nas análises dimensionais. As imagens na coloração verde correspondem aos moldes produzidos com a Borracha 1 (a), Borracha 2 (b), Borracha 3 (c), Borracha 4 (d), Borracha 5 (e) e Borracha 6 (f).

Fonte: Elaborado pelo autor, com base na pesquisa realizada. 
Com a sobreposição das nuvens de pontos, o software permite calcular a distância média entre a superfície adquirida pela digitalização e aquela utilizada como referência. Sendo assim, os tons frios (azulados) indicam pontos localizados abaixo, enquanto os tons quentes (avermelhados) indicam pontos acima desta superfície; já a cor verde mostra as regiões onde não houve erro dimensional significativo $(<0,05 \mathrm{~mm})$. Os moldes apresentaram, em média, diferenças dimensionais de 0,4 mm (Figura 7).

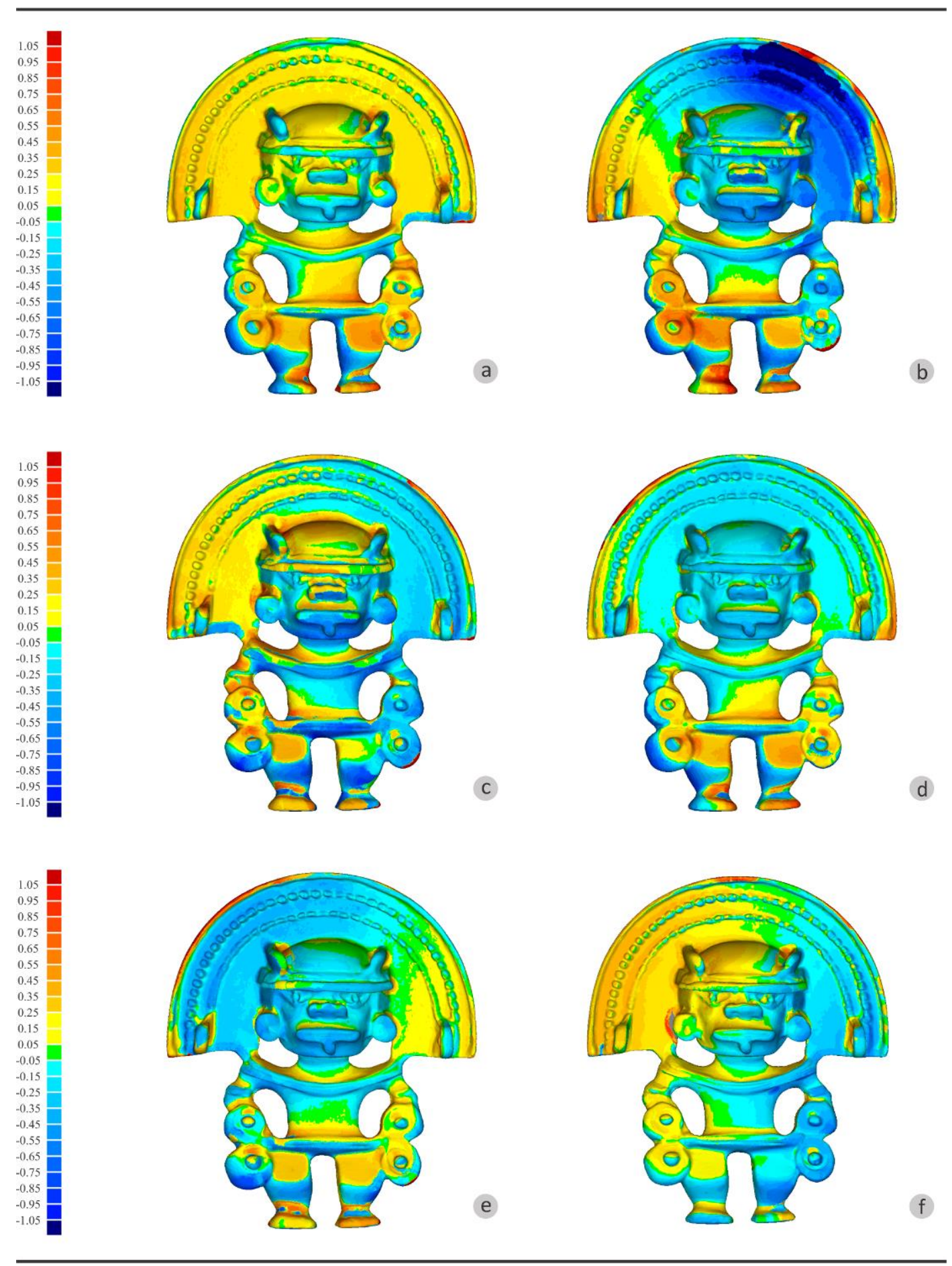

Figura 7 - Análise dimensional dos moldes de borracha de silicone. Resultado da comparação entre o modelo original e os moldes produzidos com a Borracha 1 (a), Borracha 2 (b), Borracha 3 (c), Borracha 4 (d), Borracha 5 (e) e Borracha 6 (f). Unidades em mm.

Fonte: Elaborado pelo autor, com base na pesquisa realizada. 
A tabela 2 apresenta uma compilação dos dados obtidos pela avaliação dimensional dos moldes de borracha de silicone.

Tabela 2 - Resultados das análises dos moldes de borracha de silicone quanto à taxa de encolhimento e aos erros médios.

\begin{tabular}{lcc}
\hline & Encolhimento (\%) & Diferença dimensional média $(\mathrm{mm})$ \\
\hline Borracha 1 & 3,7 & 0,46 \\
\hline Borracha 2 & 2,7 & 0,44 \\
\hline Borracha 3 & 3,2 & 0,42 \\
\hline Borracha 4 & 1,8 & 0,35 \\
\hline Borracha 5 & 4,0 & 0,42 \\
\hline Borracha 6 & 1,8 & 0,39 \\
\hline
\end{tabular}

Fonte: Elaborado pelo autor, com base na pesquisa realizada.

A taxa de encolhimento está diretamente relacionada com a quantidade de água que a borracha de silicone perde durante o processo de vulcanização. Ou seja, quanto maior a perda de água, maior será a taxa de encolhimento. Esta informação justifica a vinculação das maiores taxas às amostras das Borrachas 1, 2, 3 e 5. Entretanto, não explica o fato da Borracha 4 apresentar a mesma porcentagem de encolhimento da Borracha 6, uma vez que a cura desta última não libera calor. Acredita-se, portanto, que a diminuição do tamanho da Borracha 6 não está relacionada à perda de água, mas sim, à reação química para sua cura.

Ainda acerca do encolhimento, ao comparar as dimensões do molde e da peça de referência (Figura 6), é possível perceber a distorção de forma mais clara no sentido longitudinal da peça, devido à altura ter maior dimensão em relação à largura. Entretanto, a taxa de encolhimento medida é homogênea em ambos os eixos.

Quanto à análise dimensional, o algoritmo utilizado alinha a nuvem de pontos do molde de borracha de silicone à do modelo de referência de modo a minimizar o erro e aumentar a área contato. No caso em estudo, o alinhamento privilegia a região de maior área em torno da cabeça do hombre murciélago. Em função de o alinhamento ser feito do topo para baixo, observa-se, portanto, que o maior deslocamento entre as nuvens de pontos ocorre na região das pernas.

\section{CONCLUSÃO}

Com o presente estudo, foi possível constatar que diferentes amostras de borracha de silicone apresentam diferentes taxas de encolhimento. $O$ designer de joias deve estar atento a estes valores ao determinar as dimensões no projeto de uma peça.

Dentre os ensaios realizados, as Borrachas 4 (dureza 43 Shore A, produzida por vulcanização) e 6 (dureza 40 Shore A, produzida por cura a frio) apresentaram durezas similares aliadas à menor taxa de encolhimento: 1,8\%. Porém, de maneira geral, verificou-se que a dureza, o tempo e a temperatura - no caso das amostras produzidas por vulcanização - não apresentaram relação com a taxa de encolhimento.

Neste sentido, a contração pode ser atribuída predominantemente a reações físico-químicas ocorridas nos processos de vulcanização e cura das borrachas de silicone. Assim, propõe-se um estudo mais aprofundado na caracterização dos materiais a fim de elucidar o comportamento das amostras frente os processos de vulcanização e cura a frio. 


\section{AGRADECIMENTOS}

Este trabalho contou com o apoio da CAPES e do CNPq.

\section{REFERÊNCIAS}

GIULIANO, J.A.S. Os processos de fundição, como ferramenta na obtenção de esculturas em metal. Dissertação de Mestrado. Programa de Pós-Graduação em Engenharia de Minas, Metalúrgica e de Materiais, UFRGS, 2008.

MIDGLEY, $B$. The complete guide to sculpture, modeling and ceramics techniques and materials. New Jersey: Chartwell Books, 1986.

POHLMANN, M. et al. Mapeamento dos erros dimensionais gerados nas etapas da fabricação de joias em larga escala. In: SEMINÁRIO BRASILEIRO DE GEMOLOGIA E DESIGN DE JOIAS, 3, 2013. Anais... Santa Maria: UFSM, 2013.

REBELLO, L.H.B. A Produção de Joias e o Design. In: CONGRESSO CIENTíFICO DA UNIVERCIDADE, 2, 2007. Anais... Rio de Janeiro: UniverCidade, 2007.

RICK, C.F. Estudo da liga à base de $\mathrm{Zn}-\mathrm{Al}-\mathrm{Cu}-\mathrm{Mg}$ aplicada na fabricação de joias folhadas. Dissertação de Mestrado. Pontifícia Universidade Católica do Rio de Janeiro, Rio de Janeiro, 2006.

KLIAUGA, A.M.; FERRANTE, M. Metalurgia Básica para ourives e designers, do metal à joia. São Paulo: Edgard Blücher, 2009. 